\title{
Evolution of the Animal Apoptosis Network
}

\author{
Christian M. Zmasek and Adam Godzik \\ Program on Bioinformatics and Systems Biology, Sanford-Burnham Medical Research Institute, \\ La Jolla, California 92037 \\ Correspondence: adam@sanfordburnham.org
}

The number of available eukaryotic genomes has expanded to the point where we can evaluate the complete evolutionary history of many cellular processes. Such analyses for the apoptosis regulatory networks suggest that this network already existed in the ancestor of the entire animal kingdom (Metazoa) in a form more complex than in some popular animal model organisms. This supports the growing realization that regulatory networks do not necessarily evolve from simple to complex and that the relative simplicity of these networks in nematodes and insects does not represent an ancestral state, but is the result of secondary simplifications. Network evolution is not a process of monotonous increase in complexity, but a dynamic process that includes lineage-specific gene losses and expansions, protein domain reshuffling, and emergence/reemergence of similar protein architectures by parallel evolution. Studying the evolution of such networks is a challenging yet interesting subject for research and investigation, and such studies on the apoptosis networks provide us with interesting hints of how these networks, critical in so many human diseases, have developed.

\begin{abstract}
A poptosis, a prominent form of programmed cell death (PCD), is one of the major evolutionary innovations of multicellular eukaryotes and in some form is found in representatives of all multicellular eukaryotes (Koonin and Aravind 2002). In the animal kingdom, besides the well-studied apoptosis of mammals, insects, and nematodes, apoptosis has also been described in some of the most basal forms, such as sponges and cnidarians (Wiens et al. 2000a,b, 2001, 2003; Seipp et al. 2001; David 2005; Chipuk and Green 2006; Pankow and Bamberger 2007; Oberst et al. 2008; Lasi et al. 2010; Pernice et al. 2011). Although processes bearing similarities to apoptosis have also been observed in plants (Reape and McCabe 2010), fungi (Ma-
\end{abstract}

deo et al. 2002; Hamann et al. 2008; Sharon et al. 2009), and even in some single-cellular eukaryotes (Bidle and Falkowski 2004; Deponte 2008; Pollitt et al. 2010; Kaczanowski et al. 2011), in this review we focus specifically on apoptosis in animals. One of the most interesting questions concerning apoptosis is: How did the complex molecular network responsible for regulating and executing apoptotic cell death, which, for instance, in mammals involves around 300 genes (Doctor et al. 2003), evolve? Did this network monotonously increase in complexity over time? Did it evolve in bursts? Was the evolution linear, from a simple to a complex form, or did it involve dead ends, secondary simplifications, or other unexpected evolutionary events? These

Editors: Eric H. Baehrecke, Douglas R. Green, Sally Kornbluth, and Guy S. Salvesen

Additional Perspectives on Cell Survival and Cell Death available at www.cshperspectives.org

Copyright (C) 2013 Cold Spring Harbor Laboratory Press; all rights reserved; doi: 10.1101/cshperspect.a008649

Cite this article as Cold Spring Harb Perspect Biol 2013;5:a008649 
questions are of much more than academic interest-many diseases that are caused by errors in the apoptotic network are studied primarily in model systems, and the validity of observations in such systems for our understanding of apoptosis in human cells depends on the extent of evolutionary conservation of the specific elements of the apoptotic network (Zmasek et al. 2007).

The molecular mechanism of apoptosis was discovered and studied for the first time in the nematode Caenorhabditis elegans, which subsequently became one of the most popular model systems for the investigation of apoptosis. In this simple roundworm, three proteins (CED3, CED-4, CED-9) and later a fourth protein (EGL-1) were shown to be directly involved in apoptosis (Yuan and Horvitz 2004). Homologs of the first three $C$. elegans genes were subsequently identified in all vertebrates and in the fruit fly Drosophila melanogaster (Richardson and Kumar 2002), which quickly became a second favorite model system to study apoptosis. At the same time, a much larger apoptotic network was identified in human and mouse cells (Meier et al. 2000; Koonin and Aravind 2002; Manoharan et al. 2006). Therefore, the natural assumption was that a simple, nematode-like apoptotic network was likely to have been present in the last common ancestor of nematodes, insects, and vertebrates. However, recent sequencing of genomes of several animal species representing deeper branches of the animal phylogenetic tree forced us to reevaluate this assumption.

\section{A PROTEIN DOMAIN-CENTRIC VIEW OF FUNCTIONAL NETWORKS}

Groups of proteins involved in a specific pathway, such as apoptosis, are usually described as a "network," in which links between proteins signify their direct or indirect interactions. An overview of the core human apoptotic network is shown in Figure 2A.

Because most eukaryotic proteins are composed of multiple domains, a simplified overview and comparison of protein networks and genomes can be provided by listing domains present in the proteins forming the network. Protein domains are minimal evolutionary and structural units in proteins, retaining their structure and usually their function even when being a part of proteins with different domain architectures (Ponting and Russell 2002). Using functional assignment of protein domains, we can compare and study the evolution of the functional profiles of entire genomes (Zmasek and Godzik 2011). Here, we adopt such a domain-centric view to study and compare apoptotic networks in different species, including ancestral ones, a task made easier by the fact that many of the domains present in proteins forming this network are very characteristic and are often referred to as "apoptotic domains" (Doctor et al. 2003). For example, mammalian Apaf1 , a central gene regulating the mitochondriadependent apoptotic pathways, is composed of one CARD domain, one NB-ARC domain, and one domain with WD40 repeats, with the first two being specific to the apoptosis network. In the Amphioxus (Branchiostoma floridae) and purple sea urchin (Strongylocentrotus purpuratus) genomes, the CARD domain in the Apaf-1 homolog(s) can be replaced by a death domain (DD) and, in the starlet sea anemone (Nematostella vectensis) (Darling et al. 2005) genome, by a death effector domain (DED) (Zmasek et al. 2007), both being specific to the apoptosis network.

When investigating the evolution of proteins or protein domains, one key question is how "old" a certain protein or protein domain is, in other words, in which ancestral species it is likely to have originated. To make such inferences regarding the presence of proteins or protein domains in ancestral species, one can use the principle of Dollo parsimony, which, when applied to protein domains, states that each domain has evolved only once and seeks to minimize domain losses (Farris 1977; Zmasek and Godzik 2011). On the other hand, Dollo parsimony analysis does not allow one to estimate how many paralogs (homologous sequences that are related by a gene duplication event) of a given gene or domain existed in ancestral species. To make such inferences, explicit phylogenetic tree inference is required. 


\section{ANCESTRAL COMPLEXITY OF THE APOPTOSIS NETWORK}

The last common ancestor of all extant metazoans (animals) (dark blue in Fig. 1), in all likelihood a multicellular organism, lived around 600 million years ago (Conway Morris 2000; Hedges et al. 2004; Schierwater et al. 2009). It gave rise to the wide variety of animals alive today, ranging from "basal" organisms such as sponges and Placozoa-represented here by Trichoplax adhaerens (Schierwater 2005), one of the simplest of all animals, with a body made up of a few thousand cells of just four types, with no internal organs - to vertebrates with multiple organs and hundreds of cell types.

Recently, an increasing number of studies show that this metazoan ancestor, and to some degree even the ancestor of all eukaryotes (the so-called LECA, the last eukaryotic common

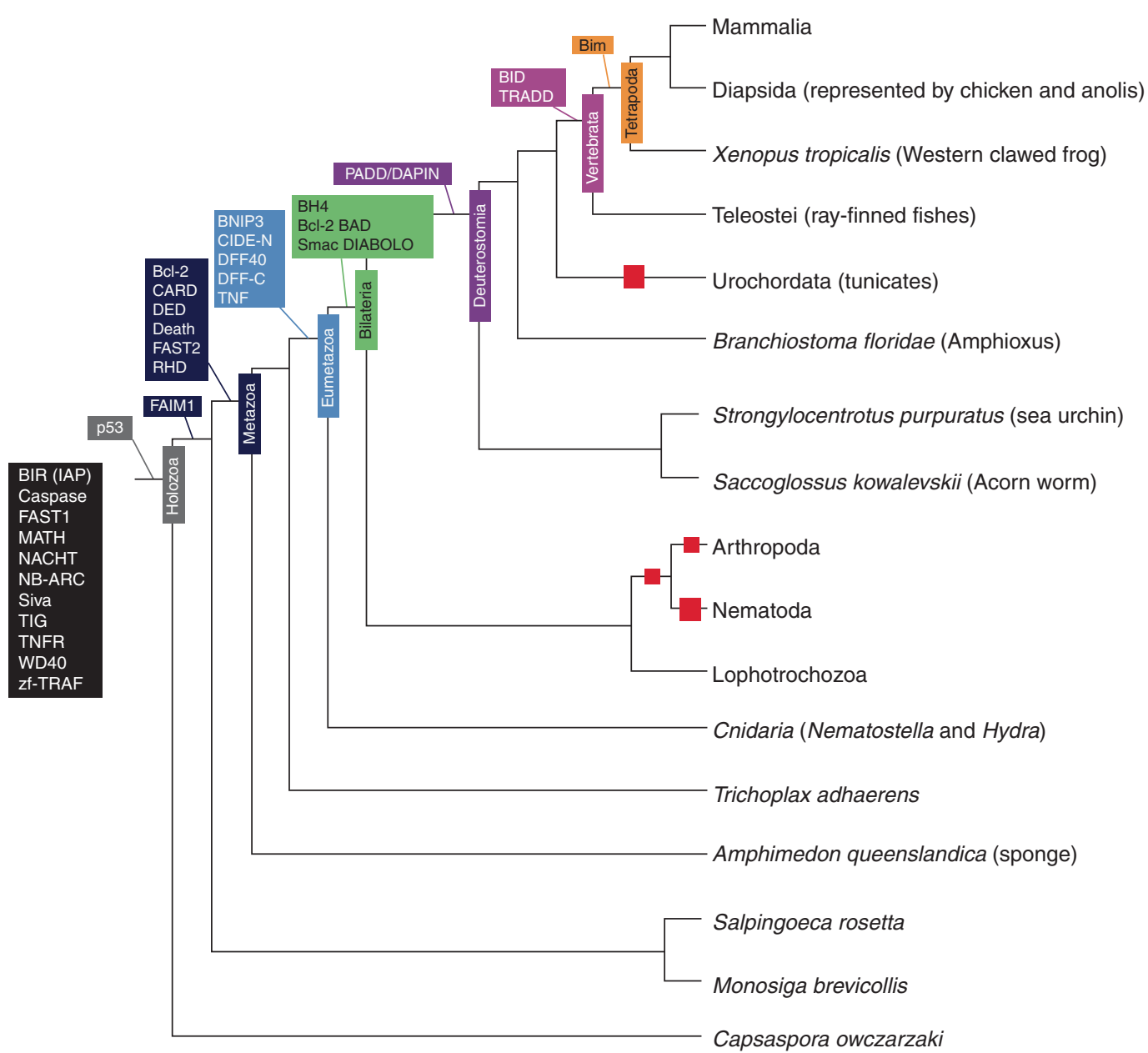

Figure 1. An overview of animal evolution overlaid with gains in apoptotic domains. Inferred gains of apoptotic domains are shown. Although domain losses are not shown in detail, the locations of significant domain losses in nematodes, insects, and tunicates are marked by red squares. Domains in the black box are estimated to have been present in the last eukaryotic common ancestor. Data are based on domain definitions from the Pfam 25.0 database and 174 completely sequenced eukaryotic genomes. The topology of the underlying eukaryotic evolutionary tree is based on data from Cameron et al. (2000), Halanych (2004), Adl et al. (2005), and Hampl et al. (2009). 
ancestor), was complex in its genome content, if not in its morphology (Zmasek and Godzik 2011, and references therein). In particular, availability of genomes of "basal" marine invertebrates, such as the demosponge Amphimedon queenslandica (the largest class in the phylum Porifera [sponges] with spicules [structural elements] consisting of fibers of the protein spongin, the mineral silica, or both) (Srivastava et al. 2010), the placozoan T. adhaerens (Srivastava et al. 2008), the hydra Hydra magnipapillata (Chapman et al. 2010), and the starlet sea anemone N. vectensis (Putnam et al. 2007), as well as representatives of nonmetazoan holozoa such as the filose amoeboid Capsaspora owczarzaki (Ruiz-Trillo et al. 2004), forced us to reconsider certain long-held assumptions regarding eukaryotic evolution. (Nonmetazoan holozoa are a group of organisms that includes animals and their closest single-celled relatives (such as Choanoflagellata) but excludes fungi.) For instance, many genes with regulatory functions not only appeared, but were also present in large families of paralogs earlier than previously thought. In part, this erroneous view of a simple LECA and a simple animal ancestor was caused by the predominant usage in molecular and cell biology research of ecdysozoan (molting animals - a group of protostome animals that includes insects and nematodes) (Aguinaldo et al. 1997) model organisms, in particular the fruit fly D. melanogaster and the nematode C. elegans. With the availability of the new genomes, it has become increasingly apparent that the genomic simplicity (such as lack of or minimal size of many pathways and smaller gene families compared with vertebrates) in these organisms does not represent an ancestral simplicity but is the result of extensive gene loss in ecdysozoans (Kortschak et al. 2003). An impressive example of this is the analysis of Nematostella Wnt genes, which revealed an unforeseen ancestral diversity: Nematostella and bilaterians share at least 11 of the 12 known Wnt subfamilies, whereas five subfamilies appear to be lost in nematodes/ insects (Kusserow et al. 2005). Similarly, it has been recently shown that the filose amoeboid $C$. owczarzaki (Ruiz-Trillo et al. 2004), a unicellular organism closely related to choanoflagellates (a group of unicellular eukaryotes, the closest living relatives of animals) and metazoans (see Fig. 1), possesses a strikingly complex repertoire of transcription factors (Sebé-Pedrós et al. 2011). Another example is the genome content of the demosponge A. queenslandica, which has been shown to be similar to more complex animals and possesses the necessary genes for most signaling pathways and transcription factors commonly associated with complex multicellular animals (Srivastava et al. 2010). Ecdysozoans (and nematodes, in particular) are not the only group of animals showing massive gene (and protein domain) loss; another example of a group of animals that show a secondarily reduced apoptotic network, as well as other reductions and loss of features, is tunicates (also known as urochordates) (Holland and GibsonBrown 2003). This observation is based on analyzing the genomic contents of three tunicates for apoptotic domains-Ciona intestinalis (Dehal et al. 2002), Ciona savignyi, and Oikopleura dioica. In the following, we show that the same phenomenon of ancestral complexity applies also to the apoptotic regulatory network.

\section{APOPTOSIS IN THE METAZOAN ANCESTOR}

For every domain, we can reason about the ancestral species in which this domain first appeared by analyzing a given domain distribution on the organismal "tree of life." More precisely, we can provide an upper estimate, as in each case some newly sequenced genome can push the time of emergence of this domain earlier. For example, the fact that sponge and mammals, but not any species outside the metazoan clade, possess death domains means that this domain probably evolved in one of the first metazoans. Applying this principle (in phylogenetic analysis called Dollo parsimony) (Farris 1977) to the set of apoptotic domains allows inference of a domain repertoire of a putative apoptosis network of the last common metazoan ancestor and of the ancestral species for major evolutionary branches. The results for such an analysis using 174 completely sequenced eukaryotic genomes, including 49 from metazoans, is shown in Figures 1 and 2. 
Evolution of the Animal Apoptosis Network
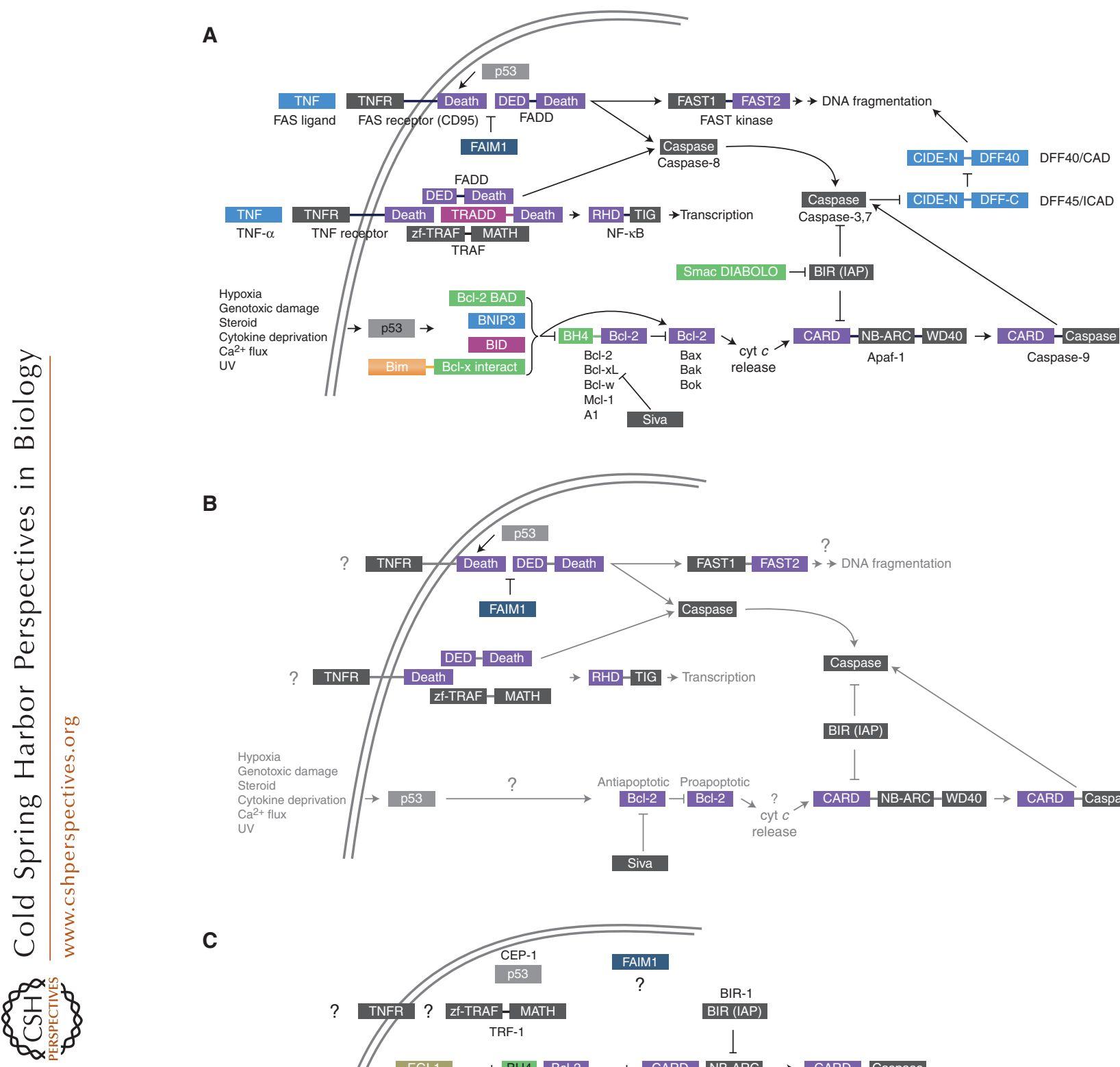

B

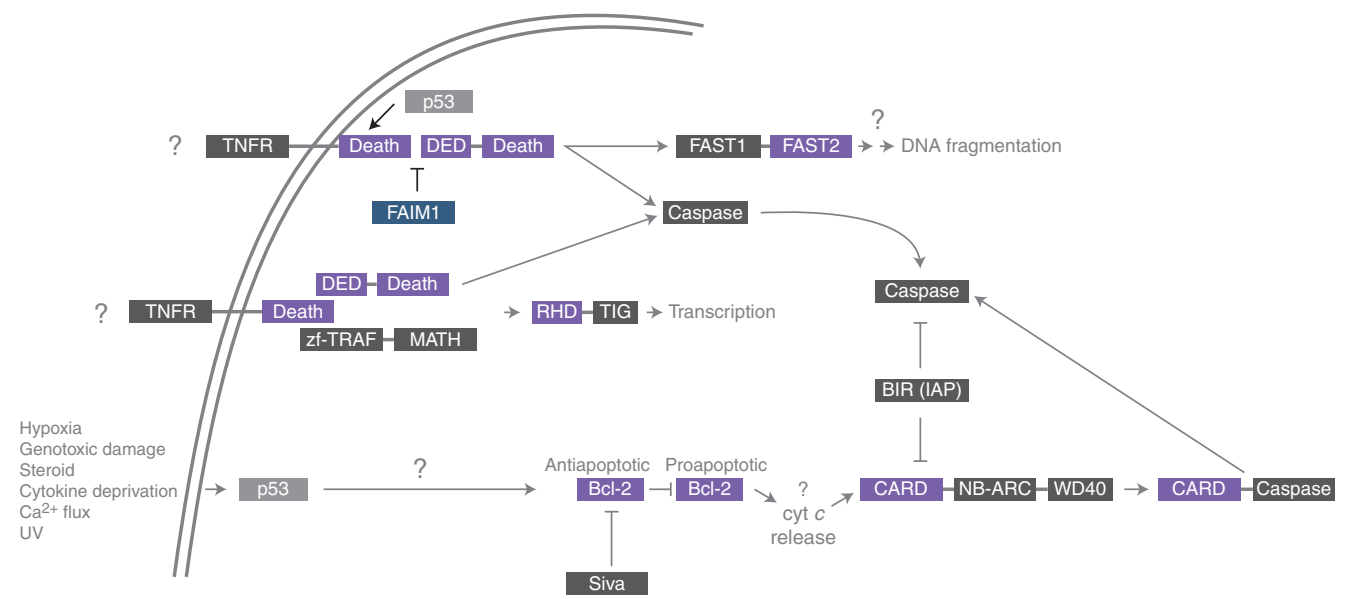

C

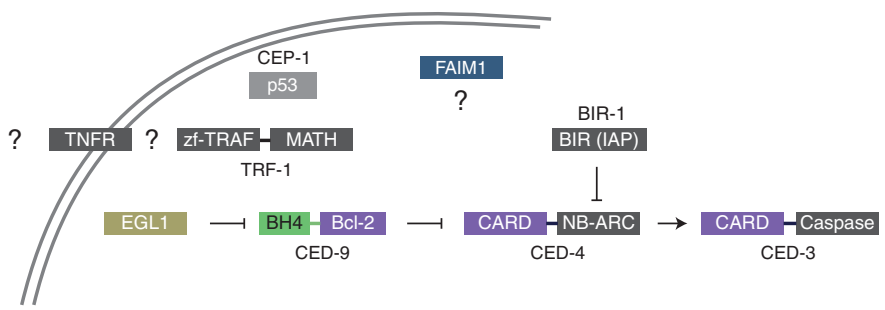

Figure 2. Evolution of the apoptosis network in animals. (A) Mammalian intrinsic and extrinsic apoptosis networks. (B) Inferred apoptosis networks of the last common metazoan ancestor. $(C)$ The apoptosis network of C. elegans as an example of a secondarily reduced network. CEP-1 is the C. elegans p53 homolog necessary for DNA damage-induced apoptosis (Schumacher et al. 2001, 2005). TRF-1 is a C. elegans TRAF homolog (Wajant et al. 1998). Data are based on domain definitions from the Pfam 25.0 database and 174 completely sequenced eukaryotic genomes. Color coding corresponds to that in Figure 1. cyt $c$, cytochrome $c$. 
It is apparent that the last common metazoan ancestor already had most components that make up extant intrinsic and extrinsic vertebrate-like apoptotic pathways: at least one TNF receptor; p53; DD (death) and DED (death effector) domains; FAIM (Fas apoptotic inhibitory molecule); Fas-activated serine/threonine (FAST) kinase; TRAIL (TNF receptor-associated factor), composed of zf-TRAF and MATH domains; NF-кB with Rel homology domain (RHD) and TIG domains; Bcl-2 (with BH1, $\mathrm{BH} 2$, and BH3 motifs, but lacking BH4); Siva; BIR (baculoviral inhibition of apoptosis protein repeat) of IAP (inhibitor of apoptosis) proteins; CARD (caspase recruitment) domains; NB-ARC; and caspases (Tian et al. 1995; Rothstein 2000; Locksley et al. 2001; Gilmore 2006; Py et al. 2007; Cao et al. 2008; Belyi et al. 2009). These domains are nearly sufficient to build a simple functional apoptotic network similar to the ones found in present-day animals, with only two core components seemingly having appeared later in eumetazoans: the DNase CAD (caspase-activated DNase) responsible for apoptotic DNA fragmentation and its inhibitor ICAD (inhibitor of CAD), and the TNF ligand (Enari et al. 1998; Locksley et al. 2001). (Eumetazoans are a clade of animals encompassing Ctenophora [comb jellies], Cnidaria [sea anemones, jellyfish, coral], and Bilateria [animals with bilateral symmetry], but excluding sponges.) It is not unlikely that the availability of more metazoan genomes outside the eumetazoan clade (such as additional sponge genomes or a first ctenophoran ["comb jelly"] genome) would push the evolution of TNF ligands and CAD/ICAD further back in time. Many of the apoptotic domains present in the last eumetazoan ancestor did not evolve in this organism and are significantly older. Examples of such proteins/domains are caspases and related proteases, as well as the NBARC domain, which are found in a wide variety of eukaryotes and, as some argue, also in bacteria and archaea (Aravind et al. 1999). On the other hand, the transcription factors p53 and NF- $\mathrm{kB}$, which were initially thought to be animal specific, appeared on the path leading toward metazoans, for it seems they have already arisen in holozoa.
EXPANSIONS OF PARALOGOUS FAMILIES OF APOPTOTIC DOMAINS SUPPORT THE PICTURE OF THE ANCESTRAL COMPLEXITY OF THE APOPTOSIS NETWORK

Most apoptotic domains are phylogenetically old, but the complexity of the apoptotic network is also created by the interplay between multiple paralogs (such as the various types of Bcl-2 or CARD family members). This expansion was also argued to be specific to "higher" animals (Aravind et al. 2001). Using the data from recently sequenced genomes, we can show that this hypothesis is also incorrect. For instance, analysis of the $S$. purpuratus (purple sea urchin) genome showed that many groups of proteins related to apoptosis underwent major expansions in this organism compared not only with ecdysozoans, but also with vertebrates (Sodergren et al. 2006). In fact, some groups of apoptosis-related proteins have 10 times more members in sea urchin than in corresponding families in vertebrates (Robertson et al. 2006; Zmasek et al. 2007). The B. floridae (Amphioxus), as well as some other genomes, show similar expansion (Zmasek et al. 2007; Zhang et al. 2008). In the following, we discuss some specific cases of apoptotic domains, focusing on paralogous expansions and secondary reduction.

\section{p53}

p53 homologs are not only present in all animals sequenced so far, but also in the choanoflagellate Monosiga brevicollis (King et al. 2008; Belyi et al. 2009) and, according to our analysis, even in the filose amoeboid C. owczarzaki (RuizTrillo et al. 2004). Therefore, the origin of p53 is likely to predate the rise of animals. Humans as well as most other mammals have three p53 family members ( $\mathrm{p} 53, \mathrm{p} 63$, and p73). The choanoflagellates M. brevicollis and Salpingoeca rosetta (data not shown), as well as the sea anemone $N$. vectensis, have between two and three paralogs that cannot be assigned to any of the mammalian subtypes but that have been argued to resemble a hybrid of the mammalian types, whereas most insects and C. elegans contain one homolog that is a combination of p63 and 
p73 (Belyi et al. 2009). Despite this, functions of the early p53 homologs are close to those of the mammalian ones, because the C. elegans homolog is necessary for DNA damage-induced apoptosis (Schumacher et al. 2001, 2005) and the Nematostella ones for UV-induced cell death (Pankow and Bamberger 2007).

\section{BIR}

BIR domains are present in the inhibitors of apoptotic proteins (Salvesen and Duckett 2002). Homologs of these domains are found in animals, fungi, and various single-cell eukaryotes, but so far they have not been found in plant genomes. The evolutionary history of BIR-containing proteins is complex, with numerous domain duplications and insertions, resulting in many proteins with different domain combinations (Verhagen et al. 2001; Cao et al. 2008). In particular, proteins with BIR and NACHT domains appear to be specific to amniotes (mammals, birds, reptiles), whereas the BIR and CARD combinations are likely to be specific for vertebrates. On the other hand, most BIR-containing proteins outside the bilaterian clade are single-domain proteins (based on the analysis of 174 eukaryotic genomes for domain content) (CM Zmasek and A Godzik, unpubl.). Although this family shows no significant secondary reduction in ecdysozoans, basal metazoans also possess multiple BIR domain-containing proteins. For example, $A$. queenslandica is estimated to contain about six proteins with BIR domains, and the cnidarians $N$. vectensis and $H$. magnipapillata both possess three proteins with BIR domains (data not shown).

\section{Apaf-1}

The Apaf-1 central nucleotide binding (NBARC, or nucleotide-binding adaptor shared by Apaf-1, R proteins, and CED-4) domain is a member of a specific branch of the very large family of $\mathrm{AAA}^{+}$ATPases and is distantly homologous to, but distinctively different from, other nucleotide-binding domains present in other apoptosis-related proteins, such as the NACHT domain present in families of proteins involved in immunity (van der Biezen and Jones 1998; Neuwald et al. 1999; Inohara et al. 2005). Detailed phylogenetic analysis of the NB-ARC domain shows an unexpected picture of a paralogous expansion in early animals, followed by contraction in both ecdysozoans and vertebrates. The full set of paralogs is present in Nematostella, with different branches being lost in the nematode/insect branch and in vertebrates, thus leaving nematodes/insects without orthologs of human Apaf-1. In addition, several Nematostella and amphioxus homologs form additional subfamilies, which were lost in both nematodes/insects and vertebrates, indicating an evolutionary history for Apaf-1 predecessors rich in gene duplications and gene losses (Zmasek et al. 2007).

The functional variations among different branches of the Apaf-1 family are illustrated by their different domain organizations. Human Apaf-1 and its Nematostella, Amphioxus, and sea urchin orthologs show the same or similar domain organization (CARD-NB-ARC-WD40 repeats). Nematode and most, but not all, insect sequences seem to lack WD40 repeats, suggesting that the loss of the receptor domain of CED-4 is a (relatively) recent event, specific to the nematode/insect branch. The full repertoire of CED4/Apaf-1 homologs in sea urchin, Amphioxus, and Nematostella contains proteins with additional domain combinations, including replacement of the single CARD domain at the amino terminus with pairs of CARD domains (Nematostella and Amphioxus), death domains (Amphioxus, sea urchin, and $H$. magnipapillata), death effector domains (Nematostella, Amphioxus, and the hemichordate [Cameron et al. 2000] Saccoglossus kowalevski [data not shown]), and TIR domains (Amphioxus), all of which function as protein - protein interaction facilitators. At the carboxyl terminus, the WD40 repeats are occasionally missing, replaced by TPR repeats or supplemented by double death domain repeats (Robertson et al. 2006; Zmasek et al. 2007).

The presence of numerous CED-4/Apaf-1 homologs in the common ancestor of Bilateria and Cnidaria suggests that initially there might 
have been several mechanisms to activate the intrinsic apoptosis pathways and/or several downstream pathways activated by similar signals and that the mechanism of human Apaf-1 and its vertebrate orthologs present only one of several possibilities. ("Orthologs" are homologous sequences that are related by a speciation event; in contrast to a common misuse of this term, orthology does not imply functional equivalence, and functional equivalence does not imply orthology.) The diverse domain architecture of Apaf-1 homologs also suggests that functional differences in this family could include both the sensing mechanism (carboxyterminal receptor domains) and the downstream recruitment function (amino-terminal protein-protein interaction domains). These findings also explain why the biochemical/structural mechanism of C. elegans CED-4 and Drosophila Dark can be significantly different from human Apaf-1.

\section{Bcl-2}

In the case of Bcl-2, members of major subfamilies were most likely already present in the early metazoan ancestors but were subsequently lost in nematodes and insects. Detailed phylogenetic analysis of the roughly 11 multimotif Bcl-2 family members of the sea anemone $N$. vectensis has shown that the Bax, Bak, and Bok groups of proapoptotic Bcl-2 homologs appear to be ancient and that each has at least one wellsupported ortholog in Nematostella. The other Nematostella Bcl-2 family members are difficult to assign to a specific subtype, although one of them has been shown to contain a region with a weak similarity to the $\mathrm{BH} 4$ motif, thus making it similar to the Bcl-2/Bcl-x branch of the Bcl-2 family. Recently, a very similar finding has been reported for another cnidarian species-the freshwater polyp Hydra. This animal has been shown to possess seven Bcl-2-like and two Baklike proteins (Lasi et al. 2010). This is in sharp contrast to the model organisms $D$. melanogaster, which contains only two Bcl-2 family genes belonging to the Bok group (Debcl and Buffy), and C. elegans, which has one (CED-9) (Zmasek et al. 2007).

\section{Caspases}

The final step in apoptosis is proteolysis of a variety of target proteins in the cell by "effector" caspases, which are activated in a proteolytic cascade by several "apical” ("initiator") caspases (Riedl and Shi 2004). Both types are clearly present in all animals. Yet, again, Nematostella, Hydra, Amphioxus, and sea urchin have representatives of more subtypes than nematodes and insects (Zmasek et al. 2007; Lasi et al. 2010). Although the caspase family appears to be specific to animals, related cysteine proteases (para- and metacaspases) can be found in a broad range of eukaryotes (Lamkanfi 2002).

\section{REFINEMENT OF APOPTOSIS IN MAMMALS}

Although most key apoptotic domains were already present in the last metazoan ancestor, the path toward the vertebrate network is accompanied by the further acquisition of domains with regulatory functions such as various proapoptotic regulators from the $\mathrm{Bcl}-2$ extended family, characterized by the presence of the $\mathrm{BH} 3$ motif (and lack of BH1, BH2, and BH4 motifs-e.g., Bad, Bid, and Bim). Another mammal-specific addition to the apoptosis network includes Smac DIABLO (see Figs. 1 and 2A) (Du et al. 2000; Verhagen et al. 2000), a mitochondrial protein that positively regulates apoptosis by eliminating the inhibitory effect of IAPs (inhibitor of apoptosis proteins). In Drosophila, the antiapoptotic activity of IAPs is removed by the three proteins Reaper, Grim, and Hid, which therefore have been termed functional homologs of the mammalian protein Smac DIABLO (Chai et al. 2000).

\section{CELL DEATH IN FUNGI, PLANTS, AND UNICELLULAR EUKARYOTES}

Fungi, plants, and even some unicellular eukaryotes have been shown to be able to execute forms of programmed cell death upon coming under various types of environmental stresses (Bidle and Falkowski 2004; Deponte 2008; Affenzeller et al. 2009; Pollitt et al. 2010). As 
mentioned above, some domains with key functions in the metazoan apoptosis program, such as caspases, BIR, and NB-ARC, have been shown to be present in various nonanimal eukaryotes, including fungi, plant, and unicellular eukaryote species-and thus they must have been present in the LECA (the last eukaryotic common ancestor). On the other hand, many other key apoptotic domains or proteins are animal specific (e.g., Bcl-2, DED, and DD). The set of domains absent in the LECA, fungi, plants, and unicellular eukaryotes is so large that at this point we cannot reconstruct a functional apoptotic network in the LECA. Of course, it is also entirely possible that cell death in these species relies on an entirely different molecular mechanism.

\section{APOPTOSIS AND INNATE IMMUNITY}

In mammals, apoptosis and innate immunity form distinct, but closely coupled networks. For example, numerous caspases act both as effectors and/or initiators of apoptosis but also have nonapoptotic functions (such as being components of the inflammasome, regulation of B cells) (Siegel 2006). Analysis of genomes of invertebrates suggests that the integration between these two networks could have been much closer in ancestral species and may be pointing to some as-yet-unrecognized connections between these networks in higher organisms. Such unexpected connections are continuously being discovered (Bertrand et al. 2009).

\section{CONCLUSIONS}

With the availability of new invertebrate genomes, we can now state unequivocally that even the last metazoan ancestor was likely to have had a complex apoptotic machinery, which could have been more similar to the mammalian than to the nematode form. Furthermore, an increasing number of studies show apoptosislike cell death in unicellular organisms, and many domains involved in apoptosis have already been present in the last eukaryotic common ancestor and even in bacteria, even though some key domains or proteins appear to be animal specific (Bcl-2, death effector domain, death domain) (Koonin and Aravind 2002; Zmasek and Godzik 2011). It is clear that apoptosis may be as old as eukaryotes and that it existed in the form resembling that seen in extant animals already hundreds of millions of years ago. At the same time, we see dynamic evolution of this network, including massive losses in some lineages (e.g., ecdysozoans and tunicates), recruitment of novel domains (mammals), and dramatic expansions and contractions of individual families. When combined with frequent domain reshuffling and emergence/reemergence of similar protein architectures by parallel evolution, we can argue that evolution of pathways such as apoptosis does not proceed by a gradual increase from simpler to more complex forms, but instead involves frequent rewiring and reshuffling, expansions and contractions, making it more interesting, but also more challenging, to understand.

\section{REFERENCES}

Adl SM, Simpson AGB, Farmer Ma, Andersen Ra, Anderson OR, Barta JR, Bowser SS, Brugerolle G Fensome Ra, Fredericq S, et al. 2005. The new higher level classification of eukaryotes with emphasis on the taxonomy of protists. J Eukaryot Microbiol 52: 399451.

Affenzeller MJ, Darehshouri A, Andosch A, Lütz C, LützMeindl U. 2009. Salt stress-induced cell death in the unicellular green alga Micrasterias denticulata. J Exp Bot 60: 939-954.

Aguinaldo AMA, Turbeville JM, Linford LS, Rivera MC, Garey JR, Raff RA, Lake JA. 1997. Evidence for a clade of nematodes, arthropods and other moulting animals. Nature 387: 489-493.

Aravind L, Dixit VM, Koonin EV. 1999. The domains of death: Evolution of the apoptosis machinery. Trends Biochem Sci 24: 47-53.

Aravind L, Dixit VM, Koonin EV. 2001. Apoptotic molecular machinery: Vastly increased complexity in vertebrates revealed by genome comparisons. Science 291: 12791284.

Belyi VA, Ak P, Markert E, Wang H, Hu W, Puzio-Kuter A, Levine AJ. 2009. The origins and evolution of the p53 family of genes. Cold Spring Harb Perspect Biol 2: a001198.

Bertrand MJM, Doiron K, Labbé K, Korneluk RG, Barker PA, Saleh M. 2009. Cellular inhibitors of apoptosis CIAP1 and CIAP2 are required for innate immunity signaling by the pattern recognition receptors NOD1 and NOD2. Immunity 30: 789-801. 
Bidle KD, Falkowski PG. 2004. Cell death in planktonic, photosynthetic microorganisms. Nat Rev Microbiol 2: 643-655.

Cameron CB, Garey JR, Swalla BJ. 2000. Evolution of the chordate body plan: New insights from phylogenetic analyses of deuterostome phyla. Proc Natl Acad Sci 97: 4469-4474.

Cao L, Wang Z, Yang X, Xie L, Yu L. 2008. The evolution of BIR domain and its containing proteins. FEBS Lett 582: 3817-3822.

Chai J, Du C, Wu JW, Kyin S, Wang X, Shi Y. 2000. Structural and biochemical basis of apoptotic activation by Smac/ DIABLO. Nature 406: 855-862.

Chapman JA, Kirkness EF, Simakov O, Hampson SE, Mitros T, Weinmaier T, Rattei T, Balasubramanian PG, Borman J, Busam D, et al. 2010. The dynamic genome of Hydra. Nature 464: 592-596.

Chipuk JE, Green DR. 2006. Dissecting p53-dependent apoptosis. Cell Death Diff 13: 994-1002.

Conway Morris S. 2000. The Cambrian "explosion": Slowfuse or megatonnage? Proc Natl Acad Sci 97: 4426-4429.

Darling JA, Reitzel AR, Burton PM, Mazza ME, Ryan JF Sullivan JC, Finnerty JR. 2005. Rising starlet: The starlet sea anemone, Nematostella vectensis. BioEssays 27: 211 221.

David CN. 2005. Hydra and the evolution of apoptosis. Integr Comp Biol 45: 631-638.

Dehal P, Satou Y, Campbell RK, Chapman J, Degnan B, De Tomaso A, Davidson B, Di Gregorio A, Gelpke M, Goodstein DM, et al. 2002. The draft genome of Ciona intestinalis: Insights into chordate and vertebrate origins. Science 298: 2157-2167.

Deponte M. 2008. Programmed cell death in protists. Biochim Biophys Acta 1783: 1396-1405.

Doctor KS, Reed JC, Godzik A, Bourne PE. 2003. The apoptosis database. Cell Death Diff 10: 621-633.

Du C, Fang M, Li Y, Li L, Wang X. 2000. Smac, a mitochondrial protein that promotes cytochrome $c$-dependent caspase activation by eliminating IAP inhibition. Cell 102: 33-42.

Enari M, Sakahira H, Yokoyama H, Okawa K, Iwamatsu A, Nagata S. 1998. A caspase-activated DNase that degrades DNA during apoptosis, and its inhibitor ICAD. Nature 391: $43-50$.

Farris JS. 1977. Phylogenetic analysis under Dollo's law. Syst Zool 26: 77-88.

Gilmore TD. 2006. Introduction to NF-кB: Players, pathways, perspectives. Oncogene 25: 6680-6684.

Halanych KM. 2004. The new view of animal phylogeny. Annu Rev Ecol Evol Syst 35: 229-256.

Hamann A, Brust D, Osiewacz HD. 2008. Apoptosis pathways in fungal growth, development and ageing. Trends Microbiol 16: 276-283.

Hampl V, Hug L, Leigh JW, Dacks JB, Lang BF, Simpson AGB, Roger AJ. 2009. Phylogenomic analyses support the monophyly of Excavata and resolve relationships among eukaryotic "supergroups." Proc Natl Acad Sci 106: 3859-3864.
Hedges S, Blair J, Venturi M, Shoe J. 2004. A molecular timescale of eukaryote evolution and the rise of complex multicellular life. BMC Evol Biol 4: 2.

Holland LZ, Gibson-Brown JJ. 2003. The Ciona intestinalis genome: When the constraints are off. BioEssays 25: $529-532$.

Inohara, Chamaillard, McDonald C, Nuñez G. 2005. NODLRR proteins: Role in host-microbial interactions and inflammatory disease. Annu Rev Biochem 74: 355-383.

Kaczanowski S, Sajid M, Reece SE. 2011. Evolution of apoptosis-like programmed cell death in unicellular protozoan parasites. Parasit Vectors 4: 44.

King N, Westbrook MJ, Young SL, Kuo A, Abedin M, Chapman J, Fairclough S, Hellsten U, Isogai Y, Letunic I, et al. 2008. The genome of the choanoflagellate Monosiga brevicollis and the origin of metazoans. Nature 451: $783-$ 788.

Koonin EV, Aravind L. 2002. Origin and evolution of eukaryotic apoptosis: The bacterial connection. Cell Death Differ 9: 394-404.

Kortschak RD, Samuel G, Saint R, Miller DJ. 2003. EST analysis of the cnidarian Acropora millepora reveals extensive gene loss and rapid sequence divergence in the model invertebrates. Curr Biol 13: 2190-2195.

Kusserow A, Pang K, Sturm C, Hrouda M, Lentfer J, Schmidt HA, Technau U, Haeseler Av, Hobmayer B, Martindale MQ, et al. 2005. Unexpected complexity of the Wnt gene family in a sea anemone. Nature 433: 156160 .

Lamkanfi M. 2002. Alice in caspase land. A phylogenetic analysis of caspases from worm to man. Cell Death Differ 9: $358-361$.

Lasi M, Pauly B, Schmidt N, Cikala M, Stiening B, Kasbauer T, Zenner G, Popp T, Wagner A, Knapp RT, et al. 2010. The molecular cell death machinery in the simple cnidarian Hydra includes an expanded caspase family and pro- and anti-apoptotic Bcl-2 proteins. Cell Res 20: $812-825$.

Locksley RM, Killeen N, Lenardo MJ. 2001. The TNF and TNF receptor superfamilies: Integrating mammalian biology. Cell 104: 487-501.

Madeo F, Herker E, Maldener C, Wissing S, Lächelt S, Herlan M, Fehr M, Lauber K, Sigrist SJ, Wesselborg S. 2002. A caspase-related protease regulates apoptosis in yeast. Mol Cell 9: 911-917.

Manoharan A, Kiefer T, Leist S, Schrader K, Urban C, Walter D, Maurer U, Borner C. 2006. Identification of a "genuine" mammalian homolog of nematodal CED-4: Is the hunt over or do we need better guns? Cell Death Differ 13: $1310-1317$.

Meier P, Finch A, Evan G. 2000. Apoptosis in development. Nature 407: 796-801.

Neuwald AF, Aravind L, Spouge JL, Koonin EV. 1999. AAA ${ }^{+}$: A class of chaperone-like ATPases associated with the assembly, operation, and disassembly of protein complexes. Genome Res 9: 27-43.

Oberst A, Bender C, Green DR. 2008. Living with death: The evolution of the mitochondrial pathway of apoptosis in animals. Cell Death Differ 15: 1139-1146.

Pankow S, Bamberger C. 2007. The p53 tumor suppressorlike protein nvp63 mediates selective germ cell death in 
the sea anemone Nematostella vectensis. PloS ONE 2: e782.

Pernice M, Dunn SR, Miard T, Dufour S, Dove S, HoeghGuldberg O. 2011. Regulation of apoptotic mediators reveals dynamic responses to thermal stress in the reef building coral Acropora millepora. PLoS ONE 6: e16095.

Pollitt LC, Colegrave N, Khan SM, Sajid M, Reece SE. 2010. Investigating the evolution of apoptosis in malaria parasites: The importance of ecology. Parasit Vectors 3: 105.

Ponting CP, Russell RR. 2002. The natural history of protein domains. Annu Rev Biophys Biomol Struct 31: 45-71.

Putnam NH, Srivastava M, Hellsten U, Dirks B, Chapman J, Salamov A, Terry A, Shapiro H, Lindquist E, Kapitonov VV, et al. 2007. Sea anemone genome reveals ancestral eumetazoan gene repertoire and genomic organization. Science 317: 86-94.

Py B, Bouchet J, Jacquot G, Sol-Foulon N, Basmaciogullari S, Schwartz O, Biard-Piechaczyk M, Benichou S. 2007. The Siva protein is a novel intracellular ligand of the CD4 receptor that promotes HIV-1 envelope-induced apoptosis in T-lymphoid cells. Apoptosis 12: 1879-1892.

Reape TJ, McCabe PF. 2010. Apoptotic-like regulation of programmed cell death in plants. Apoptosis 15: 249256.

Richardson H, Kumar S. 2002. Death to flies: Drosophila as a model system to study programmed cell death. J Immunol Methods 265: 21-38.

Riedl SJ, Shi Y. 2004. Molecular mechanisms of caspase regulation during apoptosis. Nat Rev Mol Cell Biol 5: 897-907.

Robertson AJ, Croce J, Carbonneau S, Voronina E, Miranda E, McClay DR, Coffman JA. 2006. The genomic underpinnings of apoptosis in Strongylocentrotus purpuratus. Dev Biol 300: 321-334.

Rothstein TL. 2000. Inducible resistance to Fas-mediated apoptosis in B cells. Cell Res 10: 245-266.

Ruiz-Trillo I, Inagaki Y, Davis LA, Landfald B, Roger AJ. 2004. Capsaspora owczarzaki is an independent opisthokont lineage. Curr Biol 14: R946-R947.

Salvesen GS, Duckett CS. 2002. IAP proteins: Blocking the road to death's door. Nat Rev Mol Cell Biol 3: 401410.

Schierwater B. 2005. My favorite animal, Trichoplax adhaerens. BioEssays 27: 1294-1302.

Schierwater B, Eitel M, Jakob W, Osigus H-J, Hadrys H, Dellaporta SL, Kolokotronis S-O, Desalle R. 2009. Concatenated analysis sheds light on early metazoan evolution and fuels a modern "urmetazoon" hypothesis. PLoS Biol 7: e20.

Schumacher B, Hofmann K, Boulton S, Gartner A. 2001. The C. elegans homolog of the p53 tumor suppressor is required for DNA damage-induced apoptosis. Curr Biol 11: $1722-1727$.

Schumacher B, Hanazawa M, Lee M-H, Nayak S, Volkmann K, Hofmann ER, Hofmann R, Hengartner M, Schedl T, Gartner A. 2005. Translational repression of C. elegans $\mathrm{p} 53$ by GLD-1 regulates DNA damage-induced apoptosis. Cell 120: 357-368.
Sebé-Pedrós A, de Mendoza A, Lang BF, Degnan BM, RuizTrillo I. 2011. Unexpected repertoire of metazoan transcription factors in the unicellular holozoan Capsaspora owczarzaki. Mol Biol Evol 28: 1241-1254.

Seipp S, Schmich J, Leitz T. 2001. Apoptosis—A death-inducing mechanism tightly linked with morphogenesis in Hydractina echinata (Cnidaria, Hydrozoa). Development 128: $4891-4898$.

Sharon A, Finkelstein A, Shlezinger N, Hatam I. 2009. Fungal apoptosis: Function, genes and gene function. FEMS Microbiol Rev 33: 833-854.

Siegel RM. 2006. Caspases at the crossroads of immune-cell life and death. Nat Rev Immunol 6: 308-317.

Sodergren E, Weinstock GM, Davidson EH, Cameron RA, Gibbs RA, Angerer RC, Angerer LM, Arnone MI, Burgess DR, Burke RD, et al. 2006. The genome of the sea urchin Strongylocentrotus purpuratus. Science 314: $941-$ 952.

Srivastava M, Begovic E, Chapman J, Putnam NH, Hellsten U, Kawashima T, Kuo A, Mitros T, Salamov A, Carpenter ML, et al. 2008. The Trichoplax genome and the nature of placozoans. Nature 454: 955-960.

Srivastava M, Simakov O, Chapman J, Fahey B, Gauthier MEA, Mitros T, Richards GS, Conaco C, Dacre M, Hellsten U, et al. 2010. The Amphimedon queenslandica genome and the evolution of animal complexity. Nature 466: $720-726$.

Tian Q, Taupin J, Elledge S, Robertson M, Anderson P. 1995. Fas-activated serine/threonine kinase (FAST) phosphorylates TIA-1 during Fas-mediated apoptosis. J Exp Med 182: $865-874$.

van der Biezen EA, Jones JD. 1998. The NB-ARC domain: A novel signalling motif shared by plant resistance gene products and regulators of cell death in animals. Curr Biol 8: R226-R227.

Verhagen AM, Ekert PG, Pakusch M, Silke J, Connolly LM, Reid GE, Moritz RL, Simpson RJ, Vaux DL. 2000. Identification of DIABLO, a mammalian protein that promotes apoptosis by binding to and antagonizing IAP proteins. Cell 102: 43-53.

Verhagen AM, Coulson EJ, Vaux DL. 2001. Inhibitor of apoptosis proteins and their relatives: IAPs and other BIRPs. Genome Biol 2: REVIEWS3009.

Wajant H, Mühlenbeck F, Scheurich P. 1998. Identification of a TRAF (TNF receptor-associated factor) gene in Caenorhabditis elegans. J Mol Evol 47: 656-662.

Wiens M, Krasko A, Blumbach B, Müller IM, Müller WE. 2000a. Increased expression of the potential proapoptotic molecule DD2 and increased synthesis of leukotriene B4 during allograft rejection in a marine sponge. Cell Death Diff 7: 461-469.

Wiens M, Krasko A, Mu CI, Mu WEG. 2000b. Molecular Evolution of apoptotic pathways: Cloning of key domains from sponges (Bcl-2 homology domains and death domains) and their phylogenetic relationships. J Mol Evol 50: $520-531$.

Wiens M, Diehl-Seifert B, Müller WE. 2001. Sponge Bcl-2 homologous protein (BHP2-GC) confers distinct stress resistance to human HEK-293 cells. Cell Death Differ 8: 887-898. 


\section{C.M. Zmasek and A. Godzik}

Wiens M, Krasko A, Perovic S, Müller WE. 2003. Caspase-mediated apoptosis in sponges: Cloning and function of the phylogenetic oldest apoptotic proteases from Metazoa. Biochim Biophys Acta 1593: 179189.

Yuan J, Horvitz HR. 2004. A first insight into the molecular mechanisms of apoptosis. Cell 116: S53-S56.

Zhang Q, Zmasek CM, Dishaw LJ, Mueller MG, Ye Y, Litman GW, Godzik A. 2008. Novel genes dramatically alter regulatory network topology in amphioxus. Genome Biol 9: R123.

Zmasek CM, Godzik A. 2011. Strong functional patterns in the evolution of eukaryotic genomes revealed by the reconstruction of ancestral protein domain repertoires. Genome Biol 12: R4.

Zmasek CM, Zhang Q, Ye Y, Godzik A. 2007. Surprising complexity of the ancestral apoptosis network. Genome Biol 8: R226. 


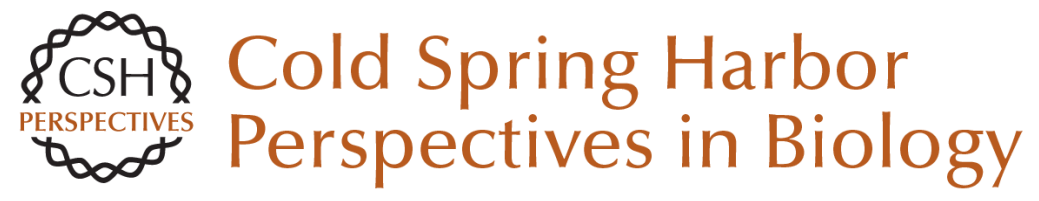

\section{Evolution of the Animal Apoptosis Network}

Christian M. Zmasek and Adam Godzik

Cold Spring Harb Perspect Biol 2013; doi: 10.1101/cshperspect.a008649

Subject Collection Cell Survival and Cell Death

Programmed Cell Death in the Evolutionary Race against Bacterial Virulence Factors

Carolyn A. Lacey and Edward A. Miao

The Evolutionary Origins of Programmed Cell

Death Signaling

Kay Hofmann

Regulation of Cell Death and Immunity by XIAP Philipp J. Jost and Domagoj Vucic

Dysregulation of Cell Death in Human Chronic Inflammation

Yue Li, Christoph Klein and Daniel Kotlarz

Cell Death in Plant Immunity

Eugenia Pitsili, Ujjal J. Phukan and Nuria S. Coll

Recent Insights on Inflammasomes, Gasdermin Pores, and Pyroptosis

Nathalia M. de Vasconcelos and Mohamed Lamkanfi

Phagocyte Responses to Cell Death in Flies Andrew J. Davidson and Will Wood

Mechanism and Regulation of

Gasdermin-Mediated Cell Death

Shiyu Xia, Louis Robert Hollingsworth IV and Hao Wu
Cell Death and Neurodegeneration Benjamin J. Andreone, Martin Larhammar and Joseph W. Lewcock

Death Receptors and Their Ligands in Inflammatory Disease and Cancer Alessandro Annibaldi and Henning Walczak

The Killer Pseudokinase Mixed Lineage Kinase Domain-Like Protein (MLKL) James M. Murphy

Neutrophil Extracellular Traps in Host Defense Sabrina Sofia Burgener and Kate Schroder

Cell-Cycle Cross Talk with Caspases and Their Substrates Patrick Connolly, Irmina Garcia-Carpio and Andreas Villunger

Cracking the Cell Death Code Carla V. Rothlin and Sourav Ghosh

BAX, BAK, and BOK: A Coming of Age for the BCL-2 Family Effector Proteins

Tudor Moldoveanu and Peter E. Czabotar

Multitasking Kinase RIPK1 Regulates Cell Death and Inflammation

Kim Newton

For additional articles in this collection, see http://cshperspectives.cshlp.org/cgi/collection/

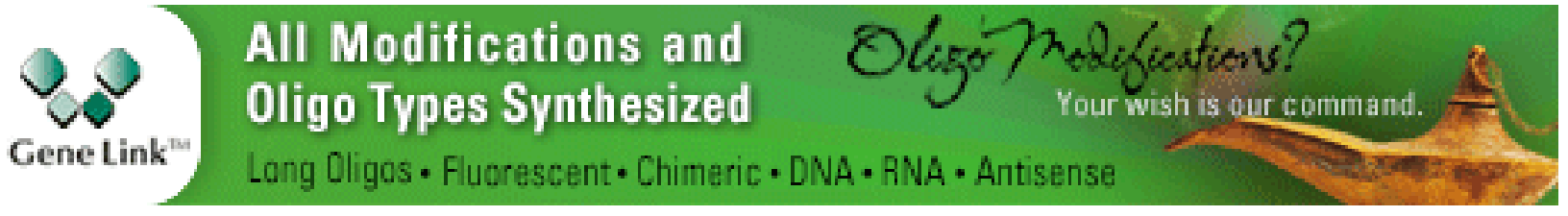

Copyright @ 2013 Cold Spring Harbor Laboratory Press; all rights reserved 
For additional articles in this collection, see http://cshperspectives.cshlp.org/cgi/collection/

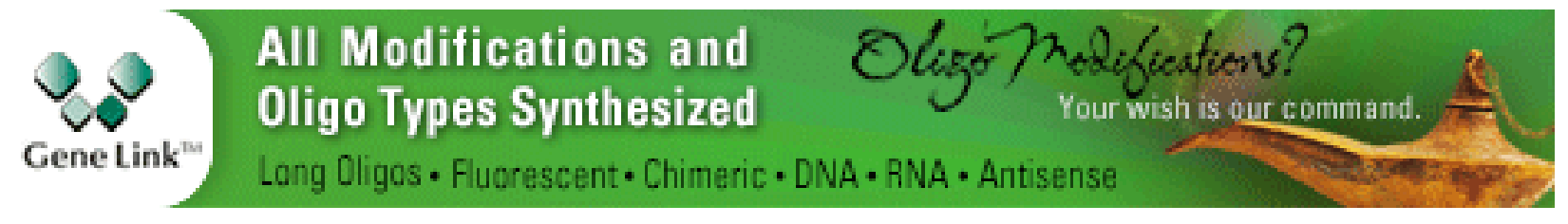

Copyright @ 2013 Cold Spring Harbor Laboratory Press; all rights reserved 